\title{
A case for integrating indigenous biodiversity into on-farm planning
}

\author{
F.J.F. MASEYK ${ }^{1}$, E.J. DOMINATI ${ }^{2}$ and A.D. MACKAY ${ }^{2}$ \\ ${ }^{1}$ The Catalyst Group, PO Box 362, Palmerston North 4440, New Zealand \\ ${ }^{2}$ AgResearch Grasslands, Private Bag 11008, Palmerston North 4422, New Zealand \\ estelle.dominati@agresearch.co.nz
}

\begin{abstract}
A considerable proportion of remaining indigenous species-dominant vegetation occurs on farmland in private ownership outside of the public conservation estate. This is particularly true of lowland settings, where native ecosystem representation is critically low. An opportunity exists to link indigenous biodiversity outcomes on private land with the need to improve the delivery of broad ecosystem services from farm systems, at the same time reducing farming's environmental footprint and improving farm resilience to major climatic events. This discussion paper (i) highlights the current status of indigenous biodiversity on-farm (ii) explores the current status of research on the integration of indigenous biodiversity into existing farm planning initiatives and (iii) demonstrates through two case studies, the potential contribution of indigenous biodiversity to economic, environmental, cultural and social outcomes on and beyond the farm. While the condition and function of indigenous vegetation contributes to conservation outcomes, this is just one, albeit important, relevant farm system outcome.
\end{abstract}

Keywords: farm planning, indigenous flora and fauna, cultural services, environmental footprint

\section{Introduction}

The last 200 years has seen the transformation from indigenous flora and fauna to exotic-dominated landscapes in many parts of New Zealand. In lowland areas this transformation has been almost complete, with urban, farming and forestry almost completely replacing indigenous forests. Thus, the diversity and abundance of indigenous species, and structural vegetation diversity is now low in these areas (Norton \& Miller 2000; Walker et al. 2006). Although there is much greater representation of woody indigenous vegetation in the hill- country (Walker et al. 2006), even these landscapes have experienced losses of indigenous biodiversity sufficient to interrupt the provision of ecosystem services such as carbon sequestration, filtering of nutrients or sediment retention. Ecosystem services flow from natural capital (and other forms of capital) and are experienced as the benefits consumed or used by humans to sustain or advance wellbeing, including the goods generated by ecosystems that people value. Natural capital comprises all abiotic and biotic elements of ecosystems and all physical, biological and chemical processes (Mace et al. 2015), including natural elements that have been modified by human activities and other capitals including social, human and built (Arias-Maldonado 2013). Thus, indigenous biodiversity contributes to natural capital.

Provisioning services are those that are extracted and consumed (e.g., food, fibre, raw materials); regulating services provide benefits derived from the regulation of ecosystem processes (e.g., regulation of water quality, mitigated storm impacts, stable climate); and cultural and social services capture those benefits that humans gain from interacting with nature (e.g., sense of place, connections to ancestors, recreation, conservation). Sustaining provision of ecosystem services is reliant on sustaining natural capital stocks - that is, avoiding the unmitigated drawdown of natural resources, and where natural capital has been depleted, actively replenishing and enhancing stocks.

While the transformation to predominantly pastoral landscapes across large areas of the country has been beneficial for food and fibre production and the export economy, it has come at a cost to our natural capital and has greatly depleted indigenous biodiversity. This is a concern because depletion of our natural capital compromises the country's long-term productive capacity, threatens food and water security, and reduces the physical, economic, cultural and social resilience of farming landscapes. Predicted impacts of climate change also make the future appear increasingly volatile. The recent public interest in water quality and fair and equitable use of water resources indicates that the farming industry will need to change to retain its long-standing social licence to operate.

New Zealand's long history of soil conservation plantings using fast growing exotic tree species with high root tensile strength to protect eroding land, provides a good example of restoration of natural capital stocks and land use capability. These plantings reinstate lost trees into otherwise pastoral dominated landscapes, contributing to structural diversity in the hill-country (Manderson \& Palmer 2006).

In addition to the long history of soil conservation plantings, riparian margin plantings and management have been a recent focus for improving and protecting natural capital on-farm, for the purposes of improving 
farm environmental performance by providing regulating services such as absorbing and filtering nutrients and other contaminants, and regulating water quality. An industry-led initiative to address impacts of dairy farming on waterways that included targets for stock exclusion from waterways was initiated in 2003 (the Clean Streams Accord) and replaced in 2012 with the Sustainable Dairying: Water Accord (the Water Accord) (https://www.dairynz.co.nz/ environment/inyour-region/sustainable-dairying-water-accord/). In response to the Accord, and due to the prevalence of regional council programmes also targeting improved water quality outcomes, planting and fencing of riparian margins to exclude stock has become a key management focus across dairy landscapes. This and soil conservation plantings are examples that illustrate how the provision of ecosystem services can be influenced through management actions targeted at specific natural capital stocks on-farm, and indeed farmers have been doing so to some degree for some time.

The ongoing and urgent need to reduce farming's environmental footprint, improving farm resilience to major climatic events, and communicating provenance and on-farm practices with the consumer, represents an opportunity to take such initiatives further to increase indigenous biodiversity representation on private land. This paper discusses: (i) the current status of indigenous biodiversity on-farm (ii) the current status of research on the integration of indigenous biodiversity into existing farm planning initiatives and (iii) demonstrates through two case studies, the potential contribution of indigenous biodiversity to economic, environmental, cultural and social outcomes on and beyond the farm, of which conservation is just one, albeit an important outcome.

\section{Current status of indigenous biodiversity on- farm}

A recent report commissioned by Beef + Lamb NZ, using land cover data derived from remote sensing (LCDB version 4.1), found that a total of 2.8 million ha of indigenous vegetation occurs on sheep and beef farms (Norton \& Pannell 2018). This is $25 \%$ of the total indigenous vegetation remaining across New Zealand, thus sheep and beef farms represent the second most important contribution to remaining indigenous vegetation cover in New Zealand, after public conservation land. In contrast, dairy farms contain only $1.4 \%$ of the total indigenous vegetation remaining. These differing statistics reflect the distinctly different landscapes that these two sectors occupy. Sheep and beef are typically found in the hill-country that includes land units unsuitable for pastoral agriculture, while dairy farming is found predominantly in lowland environments, where the vast majority of land units are highly suited to a pastoral or arable use. The small proportion of indigenous vegetation that remains at low altitude and in drier regions on-farm is critically important, as these environments are rarely represented within public conservation land, and as a consequence is an important resource for biodiversity conservation in New Zealand (Leathwick 2001). As a measure of the current level of protection (June 2016), there were a total of 4626 protected open spaces (including registered covenants, approved covenants, and formal agreements), covering 182677 ha (QEII National Trust 2017). While a major achievement by individual land owners within the sectors, this only covers a small percentage of the indigenous vegetation remaining on private land. For example, only $3 \%$ of the nearly 3 million ha of indigenous vegetation on sheep and beef farms is protected by a QEII covenant (Norton \& Pannell 2018).

\section{Relationship between the condition and function of indigenous biodiversity and outcomes on and beyond the farm}

Farm plans already collect a large amount of information on the areal extent of native bush fragments, riparian margins and wetlands, along with hectares in pasture and crops, plantation forestry, woodlots, length of shelterbelts, and the number and age of spaced planted conservation poplar and willow trees (Manderson et al. 2007). Compared with the data routinely collected on the productivity and quality of pastures, growth of forestry woodlots and effectiveness of shelterbelts and spaced planted poplar, little data are typically collected on the condition and function of bush fragments, wetlands or riparian margins. This makes it difficult to assess the effectiveness and hence the contribution these make on-farm in delaying run-off after a storm event (regulating service), reducing the risk of erosion (i.e. protecting natural capital stocks), provision of shade and shelter for livestock (generating benefits that contribute to provisioning services - food and fibre), filtering of sediments nutrients and $E$. coli in run-off water (regulating services that generate environmental benefits), sequestering carbon to regulate greenhouse gas emissions (regulating service), through to the impact on the visual appearance of landscapes (cultural services) and ecological outcomes through greater function on-farm leading to greater connectivity to indigenous biodiversity beyond the farm boundary (cultural service). Therefore, it is difficult to assess how the farm system as a whole is benefiting from the presence of biodiversity, or suffering from a lack of it. Currently, the influence of farm-scale actions on ecological function and connectivity at the landscape scale is rarely formally considered in regional 
monitoring or within farm-scale work plans, although it is an important aspect of achieving regional and national biodiversity objectives.

\section{Integrating indigenous biodiversity into farm planning}

Typically, managing biodiversity on-farm has been piecemeal, with a tendency to protect discrete fragments (e.g., remnant bush blocks or wetlands), either as a voluntary action, associated with other drivers (e.g., erosion control, stream bank protection, etc.) or in response to local government regulatory requirements. National direction for biodiversity protection on-farm is lacking, although there is currently a collaborative process underway to develop agreed recommendations for a National Policy Statement (https://www. biodiversitynz.org/). Regional and District Councils also address their statutory requirements under the Resource Management Act as it relates to biodiversity on private land in a varied manner (Maseyk \& Gerbeaux 2015). This lack of national direction has resulted in a range of policy responses across New Zealand, including in many cases a lack of attention to statutory responsibilities. As a consequence, the country has experienced a continued decline in the extent and condition of indigenous biodiversity on private land (http://www.mfe.govt.nz/publications/environmentalreporting/environment-new-zealand-2007-chapter-9land/current-state).

It is suggested that current approaches by central and local government to protect and encourage the maintenance of biodiversity on-farm have failed, largely because policies and programmes consider indigenous biodiversity in a manner that is divorced from other on-farm decisions regarding the management of resources and direct benefits to the farm systems. For example, sole emphasis on conservation objectives for a restricted number of high-value, significant areas, as is typical within many regions, comes at the expense of considering the wider functional values of indigenous biodiversity on-farm, such as erosion prevention, flood mitigation, nutrients attenuation, animal health, people well-being and so worth. Equally, the need for this emphasis is rarely communicated from the perspective of relevance to the landowner. Shifting this paradigm to one where indigenous biodiversity considerations are integrated into the farm-system and day-to-day decision-making will require a new approach. It can be unclear how individual actions on-farm, or the farm as a whole contribute to district or regional policies, or how these policies translate to necessary actions on farm. No farm is an island. Improving the protection and management of indigenous biodiversity on-farm provides another link between the farm and the wider community. Going further and actively increasing indigenous biodiversity on-farm, represents a real opportunity to meet wider societal expectations of farming, reduce farming's environmental footprint while improving farm resilience, as well as wider community well-being.

It is suggested that the existing land evaluation and farm planning process provides an established and familiar mechanism for implementing this shift (Maseyk et al. 2018b). Bringing ecological theory together with land evaluation and farm planning processes (Mackay et al. 2018) allows the goals for all aspects of the farm (e.g., nutrient management, animal management, business planning, environmental management) to be assessed side-by-side and in the context of the full range of services and values (environmental, cultural, social, and economic) provided by the farm system, and in doing so avoids relegating biodiversity to a 'nice to have' add-on to decision-making.

Implementing this will require a less soil-based approach than is currently the norm in land evaluation and farm planning processes, and additional effort in developing an ecological understanding of the landscape (Maseyk et al. 2018b). Having a clear understanding of the capacity and condition of all the farm's assets from soils to animals and biodiversity is essential for informing long-term goals and dayto-day management decisions; this equally applies to understanding biodiversity stocks. For example, a stocktake of biodiversity will require identification of indigenous flora and fauna on-farm and its connectivity and function beyond the farm boundary, as well as an assessment of its current state and condition. In a sense, this is no different to identifying and understanding the role of pasture and weed species in driving seasonal forage supply, soil stability and animal health. The stocktake should include current capacity of biodiversity to provide ecosystem services directly to the farm system as well as beyond, and range from economic (e.g., cost of pest management, impacts of shade and shelter on animal losses and health), environmental (e.g., filtering of nutrients, greenhouse gas mitigation and carbon storage of permanent woody vegetation, flood mitigation), social (e.g., recreation opportunities, vista) through to cultural (e.g., sites of significance). This will require evaluation of indigenous biodiversity assets and ecological processes on-and beyond the farm against appropriate reference values, to determine both relative condition and ecological or conservation importance. The latter will require an assessment of on-farm indigenous biodiversity assets against regional and national objectives, priorities, and regulations. This will also require consideration of the impacts of current farm practices on the condition and longevity of existing indigenous biodiversity (e.g., winter grazing within bush blocks which introduces nutrients and potentially 
weed seeds via effluent and removes the understory via trampling or consumption). By necessity, integrating biodiversity considerations into on-farm decision making will require the inclusion of a wider range of system performance measures beyond just livestock performance, Olsen P and dollars to report on the farm's performance. In doing so, biodiversity benefits on- and beyond the farm arising from on-farm decisions, and contributions to regional and national conservation objectives can be explored (Maseyk et al. 2018b).

With the practice of farm planning already well established in New Zealand (Mackay et al. 2018), the existing templates will need to be expanded to accommodate the inclusion of indigenous biodiversity and ecosystem function considerations. Existing data (such as national spatial databases and council monitoring data where it is available) can go some way towards informing the farm plan, but there is also a need to gather additional information. Critically, encapsulating biodiversity at every step of the farm planning process identifies where the farm performance can be lifted by enhancing or reintroducing biodiversity stocks. For example, excluding animals from erosion prone land units to allow natural regeneration of native scrub; reintroducing riparian margin vegetation, or reinstating hydrological flow regimes through wetland habitat. In the same manner, a greater understanding of the influence of specific farm practices on the condition of biodiversity stocks and flow of ecosystem services can be assessed (Maseyk et al. 2018b).

A good example of the limited information available on the condition of native bush at the farm scale was highlighted in a recent study examining the potential for native bush to sequester adequate carbon (C) to offset greenhouse gas emissions by livestock (Burrows et al. 2018). The two case studies below demonstrate what can currently be achieved with the limited information available on the condition of native biodiversity onfarm.

Case 1: An intensive sheep breeding and finishing enterprise located in the Upper Pohangina Valley, typical of large tracts of southern North Island hill-country. The enterprise comprises sheep, cattle and hinds for venison production on 412 ha total. This area includes 270 ha in pasture, 124 ha of established and regenerating native bush protected under a Queen Elizabeth II Trust Open Space Conservation Covenant, a small plantation of Douglas fir (Pseudotsuga menziesii) and spaced planted poplar on the LUC Class 6 and 7 land. Greenhouse gas emissions (methane, nitrous oxide, carbon dioxide) and more specifically $\mathrm{C}$ sequestration is one of the ecosystem services the native bush on the farm provides to the wider farm system so here data available to quantify this service for the farm were assessed. Emissions from this farming operation would be at the upper range of modelled emissions for sheep and beef operations (2-4.5 t CO 2 e/ha/year) reported by Smeaton et al. (2011). In the absence of adequate information on the condition and function of the native bush block, assumptions regarding the occurrence of ecological processes based on available knowledge are required (i.e. extent, age, and type of vegetation). In this case it was assumed that the potential for the farm to sequester $\mathrm{C}$ was negligible $\left(<0.1 \mathrm{t} \mathrm{CO}_{2} \mathrm{e} / \mathrm{ha} /\right.$ year), because of the advanced age of the canopy trees within the bush block, and ongoing likelihood of loss of condition due to climate (e.g. drought), or storm events (e.g. snow storms, high wind events). It is important to note that $\mathrm{C}$ stocks (e.g. standing forest, peat mires, soil carbon) in themselves do not create any offset benefit, only change (increase) in those stocks results in an offset sink by generating sequestration additional to that already occurring. If there was knowledge to show that the native bush on-farm was actively growing and accumulating $\mathrm{C}$, additional sequestration could be demonstrated. For example, if the 124 ha was sequestering $1 \mathrm{t} \mathrm{CO}_{2} \mathrm{e} / \mathrm{ha} / \mathrm{year}$, this would provide sufficient carbon credit to account for $10 \%$ of the greenhouse gas emissions generated annually by the livestock on farm. In this case, the native bush does not sequester enough $C$ to fully offset annual emissions, but does make a quantifiable contribution. Understanding the condition and function of the native bush is also important in assessing its contribution to all the other services, of which $\mathrm{C}$ sequestration is just one, and unlike other services, short-lived. This is because biomass $\mathrm{C}$ sinks are temporary, ending when the vegetation reaches a steady-state when growth and mortality/decomposition are balanced, while the other services and benefits provided by native bush, including water purification, shelter, and protecting the underlying natural capital stocks are on-going.

A second case can be drawn from a study of the riparian planting programme in the Taranaki Region designed to maintain water quality on the ring plain through the fencing and planting of riparian margins. This voluntary programme represents a major reintroduction of native species into a lowland environment where original vegetation cover has been drastically depleted, and provides insights into the value of integrating native planted riparian margins into the farm business.

Case 2: The Taranaki Regional Council instigated the first regional riparian programme in 1993, resulting in 2500 riparian plans (achieving 84\% fencing and $70 \%$ planting) covering $14500 \mathrm{~km}$ of streambank by September 2017 (https://www.trc.govt.nz/environment/ freshwater/riparian-management/). Graham et al. 
(2018) found the Taranaki riparian programme is beginning to show measurable beneficial effects on some parameters of water quality and downstream aquatic invertebrate communities. Maseyk et al. (2017) describes how some dairy farmers in the Taranaki ring plain and who have planted native vegetation within their riparian margins, identified a range of perceived benefits that extended beyond improved water quality. These benefits included increased biodiversity onfarm. Although Maseyk et al. (2017) did not quantify this perceived biodiversity outcome, there can be an assumed provision of cultural ecosystem services from the planting of riparian margins. In addition, riparian plantings can contribute to the creation of habitat and improved vista (White et al. 2014). Beyond biodiversity benefits, participating farmers stated that they obtained some immediate direct benefits to farm management and the farm system and in some instances increased productivity on-farm as a result of fencing and planting of the riparian margin in native plants. While the fencing of waterways resulted in improved efficiencies in feed budgeting, reduced staff time in mustering cows for milking, reduced cow deaths and improved staff safety, planting of the margins created a better living environment for the livestock, which includes shelter during extreme weather events and shade in summer. For staff it also created a better working environment. This was reflected in the ability to attract skilled staff (Maseyk et al. 2017). Carbon sequestration was not identified by the Taranaki ring plain farmers as a benefit flowing from planted riparian margins, but has been suggested subsequently in other studies as another potential co-benefit of a riparian planting (Shepherd et al. 2017), although the amounts of $C$ sequestered in riparian margins are small when compared with the greenhouse gas emissions from an intensive dairy operation. Maseyk et al. (2018a) in estimating the benefits of native vegetation planting within the planted riparian margins on a dairy farm, found that fenced and planted riparian margins reduced nutrient (phosphorus) and $E$. coli losses to water, increased the landscape diversity index (a measure of the visual and structural vegetation diversity across the farm and surrounding landscapes), and critically, did not impact negatively on milk production, which was consistent with the farmers experience.

\section{Conclusion}

Integrating indigenous biodiversity into farm planning presents an opportunity to bring together the businesses of farming and conservation and offers a more holistic approach to farm planning. This will be no easy task, and will require additional efforts at both national, regional and farm levels. The questions of National strategy for biodiversity and regional incentives are beyond the scope of this paper but are more than ever relevant. Demonstrating to farmers that recognising the wider benefits of biodiversity on-farm will help the whole farm system is a good place to start to help motivate the 'right' type of behaviours.

Suggestions that farming landscapes are not the place for indigenous biodiversity take a short-sighted view that overlooks the role farms play in the wider landscape. It is crucial that the boundaries are blurred between areas of the farm producing traditional commodities (food and fibre) and those non-pastoral areas of the farm which produce other benefits for and beyond the farm. Taking a more holistic approach to farm planning has the potential to provide the process to quantify and value both the on- and offfarm benefits associated with indigenous biodiversity, link biodiversity to farm performance, and identify management actions required to effect change. By increasing indigenous biodiversity on-farm the ability to withstand environmental pressures is enhanced, while operating within social expectations, and further connecting farming landscapes to the wider community.

Specific practical steps of including biodiversity into farm planning as well as understanding condition of indigenous biodiversity and the links to the provision of ecosystem services on- and beyond the farm, are all on-going research.

\section{ACKNOWLEDGEMENTS}

This work was supported by the Biodiversity and Ecosystem Services for Resource Management (BEST) project funded by the New Zealand Ministry of Business, Innovation and Employment. The authors would like to recognise funding for the preparation of the manuscript from the AgResearch Strategic Science Investment Fund.

\section{REFERENCES}

Arias-Maldonado, M. 2013. Rethinking sustainability in the Anthropocene. Environmental Politics 22: 428-446.

Burrows, L.; Wakelin, S.; Quinn, J.; Graham E.; Mackay, A. 2018. Carbon sequestration potential of non-ETS land on farms. Landcare Research Contract Report: LC3161 for Ministry Primary Industry. 85 pp.

Graham, E.; Jones-Todd, C.M.; Wadhwa, S.; Storey, R. 2018. Analysis of stream responses to riparian management on the Taranaki ring plain. NIWA Client Report No: $2018051 \mathrm{HN}$ prepared for Taranaki Regional Council.

Leathwick, J.R. 2001. New Zealand's potential forest pattern as predicted from current speciesenvironment relationships, New Zealand Journal of Botany 39: 447-464. 
Mace, G.M.; Hails, R.S.; Cryle, P.; Harlow, J.; Clarke, S.J. 2015. Towards a risk register for natural capital. Journal of Applied Ecology 52: 641-653.

Mackay, A.D.; Dominati, E.J.; Rendel, J.M.; Maseyk, F.J.F. 2018. Looking to the future of land evaluation at farm scale. New Zealand Journal of Agricultural Research 61: 1-6.

Manderson, A.; Palmer, A. 2006. Soil information for agricultural decision making: a New Zealand perspective. Soil Use and Management 22: 393-400.

Manderson, A.K.; Mackay, A.D.; Palmer, A.P. 2007. Environmental whole farm management plans: Their character, diversity, and use as agri-environmental indicators in New Zealand. Journal of Environmental Management 82: 319-331.

Maseyk, F.J.F.; Gerbeaux, P. 2015. Advances in the identification of significant habitat in two areas of contrasting biodiversity loss in New Zealand. New Zealand Journal of Ecology 39: 116-127.

Maseyk, F.; Dominati, E.; White, T.; Mackay, A. 2017. Farmer perspectives of the on-farm and off-farm pros and cons of planted multifunctional riparian margins. Land Use Policy 61: 160-170.

Maseyk, F.J.F.; Dominati, E.J.; Mackay, A.D. 2018a. Change in ecosystem service provision within a lowland dairy landscape under different riparian margin scenarios. International Journal of Biodiversity Science, Ecosystem Services \& Management 14: 17-31.

Maseyk, F.J.F.; Dominati, E.J.; Mackay, A.D. 2018 b. More than a 'nice to have': integrating indigenous biodiversity into agroecosystems in New Zealand. New Zealand Journal of Ecology. (Submitted).
Norton, B.D.A.; Miller, C.J. 2000. Some issues and options for the conservation of native biodiversity in rural New Zealand. Ecological Management \& Restoration 1: 26-34.

Norton, D.; Pannell, J. 2018. Desk-top assessment of native vegetation on New Zealand sheep and beef farms. Report for Beef+Lamb NZ. 32 pp. https:// beeflambnz.com/nortonreport

QEII National Trust. 2017. Annual Statistics. http:// www.openspace.org.nz/Site/Publications_resources/ Annual_statistics_maps_and_graphs.aspx. Accessed 14th November 2017

Shepherd, M.; Mackay, A.; Monaghan, R.; Vibart, R.; Devantier, B.; Wakelin, S.; Payn, T.; Müller, K.; Lucci, G.; Clothier, B.; Hock, B.; Harrison, D. 2017. An assessment of climate mitigation co-benefits arising from the Freshwater Reforms. Prepared for the Ministry for Primary Industries. MPI Technical Paper No: 2017/19.

Smeaton, D.C.; Cox, T.; Kerr, S.; Dynes, R. 2011. Relationships between farm productivity, profitability, N leaching and GHG emissions: a modelling approach. Proceedings of the New Zealand Grassland Association 73: 57-62.

Walker, S.; Price, R.; Rutledge, D.; Stephens, R.T.T.; Lee, W.G. 2006. Recent loss of indigenous cover in New Zealand. New Zealand Journal of Ecology 30: 169-177.

White, T.D.; Dominati, E.J.; Mackay, A.D.; Blackett, P. 2014. More than just fencing: Options for riparian zones on farm and ecosystem services valuation - A poster. Australasian Dairy Science Symposium, 1921 November 2014, Hamilton, New Zealand. 